\title{
Measuring Performance of Reverse Supply Chains in a Computer Hardware Company
}

\author{
M.B. Butar Butar, D. Sanders, G. Tewkesbury \\ ${ }^{1}$ School of Engineering, University of Portsmouth, Portsmouth, United Kingdom \\ (mde80356@myport.ac.uk)
}

\begin{abstract}
This paper focuses on measuring performance of reverse supply chains in computer hardware companies. A simple general framework of the company is presented as well as a mathematical model. This simple general model can be applied by small medium enterprises to optimise their reverse supply chain systems.
\end{abstract}

Keywords - Reverse supply chain, computer recycling, performance measurement

\section{INTRODUCTION}

The role of a Reverse Supply Chain (RSC) or reverse logistics is increasing in many industries such as the automobile industry, consumer electronics, book publishers, catalogue retailers and so [1]. Reverse Supply Chains have become relevant for two reasons: first, the environmental issues and the impact of these issues on public opinion; second the benefits that a company can obtain by the improvement of their return's processes.

Increasing attention has also been given to the RSC due to the increasing value of products and technology. Rate of return varies by industry. Some industries have high percentages of returns such as internet retailers, or computer manufacturers while others have lower percentages. Computers can be regarded as a short-lifecycle electronic product [2]. The recycling effort is having trouble dealing with high-volume short-life technological products such as cellular phones and computers [3]. The establishment of appropriate infrastructure is essential for the successful implementation of electronic waste recycling. Infrastructure determines the process methods and amount of waste that can be processed. It includes transportation, collection, recovery, and resale establishments [4].

Unlike forward supply chains, strategies for reverse supply chains are relatively unexplored and underdeveloped. However, product returns and their reverse supply chains represent an opportunity to create a value stream, instead of an automatic loss. Therefore, reverse supply chains should be a managed business processes. Although reverse supply chains and performance measurement have been discussed widely in the literature, performance measurement in reverse supply chains needs further investigation [5]. This paper will focus on performance measurement in a computer hardware reverse supply chain, particularly on computer hardware recycling and refurbishing facilities. This paper introduces:
1. A prototype model for returned product flow at a computer company.

2. Testing of the prototype with mathematical models using cost as a performance metric.

\section{BACKGROUND}

\section{A. Reverse Supply Chains(RSCs)}

A RSC is a series of activities required to retrieve a used or unused product and either dispose of it, reuse it, or resell it [6].

Companies have an option to close the RSC or leave it open. Leaving it open means the products in a reverse supply chain will go to different destinations from the original supply chain. Supply chains could also be made by creating a loop. This closed loop supply chain consists of a reverse supply chain and closed loop to connect it to the original forward supply chain [7]. Guide and Wassenhove [8] stated that companies that had been most successful with their RSC were those that closely coordinated them with their forward supply chain, creating a closed-loop system.

To make rational decisions about the structure of a reverse supply chain, Guide and van Wassenhove [9] declared it best to divide a chain into five key components and then to analyse options, costs and benefits for each of them.

Users may return products for different reasons at different stages in the product lifecycle [10]. Numerous classifications of product returns have been given by several authors in the past according to different categories and some are shown in Table 1.

TABLE I

CLASSIFICATION OF PRODUCT RETURNS

\begin{tabular}{|l|l|}
\hline Authors & Categories of Product Returns \\
\hline Rogers and Tibben-Lembke [11] & Reverse flow of products \\
& Reverse flow of packaging \\
\hline De Brito and Dekker [12] & Manufacturing phase \\
& Distribution phase \\
& Customer use returns \\
\hline
\end{tabular}

One factor in achieving an effective reverse supply chain is an efficient establishment of schedules, transportation and networks [13]. Fleischmann et al [14] described a network model for a recovery network. There were three facilities involved: 
- disassembly centres which house inspection and separation activities,

- factories for reprocessing and/or new production,

- and distribution warehouses to keep an inventory of unprocessed and processed returns.

In reverse supply chains, there are additional processes compared with forward supply chains. The processes are dependent on the condition (quality) of returns and appropriate channels need to be chosen based on recovery options [15]. For example, in the aircraft industry, very high quality is required for safely.

Thierry et al [16] presented a category of product recovery options where each of them implied collection of used products and components, reprocessing and redistribution. The only thing that was different involved reprocessing activities. There were five main activities: repairing; refurbishing; remanufacturing; cannibalisation (in the context of component reuse) and recycling.

The definition used in this paper is that a Recovery Plant facility is where parts are refurbished, while a Manufacturing Plant is where parts are produced.

\section{B. Performance Measurement}

Performance measurement is often discussed but rarely defined. There are many reasons why companies measure their performance. Cuthbertson and Piotrowicz [17] mention measuring supply chain performance to increase understanding, collaboration and integration between supply chain members. It also helps companies to target profitable market segments or identify a suitable service definition. Furthermore, performance measurement is an activity to reach predefined goals derived from company's strategy objectives [5].

There are a large number of performance measures discussed in the literature. In the earlier literature, performance measures were usually divided into costrelated and non-cost-related performance measures. Stock [18] classified a group of individual performance measures based on the terms of the five manufacturing performance objectives: quality; speed; dependability; flexibility and cost. In Stock and Mulki paper [19], examples of different performance measures are listed under these five categories.

\section{Reverse Supply Chain at Computer Company}

Key factors in recycling of e-waste are collection, sorting and recovery, recycling and disposal, as shown in Figure 1. This figure is a simplified flow diagram for the recycling of an electronic product.

Returned products are collected from many widespread sources and consolidated for further inspection, handling and processing. Therefore, reverse logistics is more complex than forward logistics as there are many actors involved in the processes. Since reverse shipments tend to be smaller, less frequent and mixed, the costs of transportation, handling and inventory holding for reverse logistics are always higher than forward logistics for new products [11].

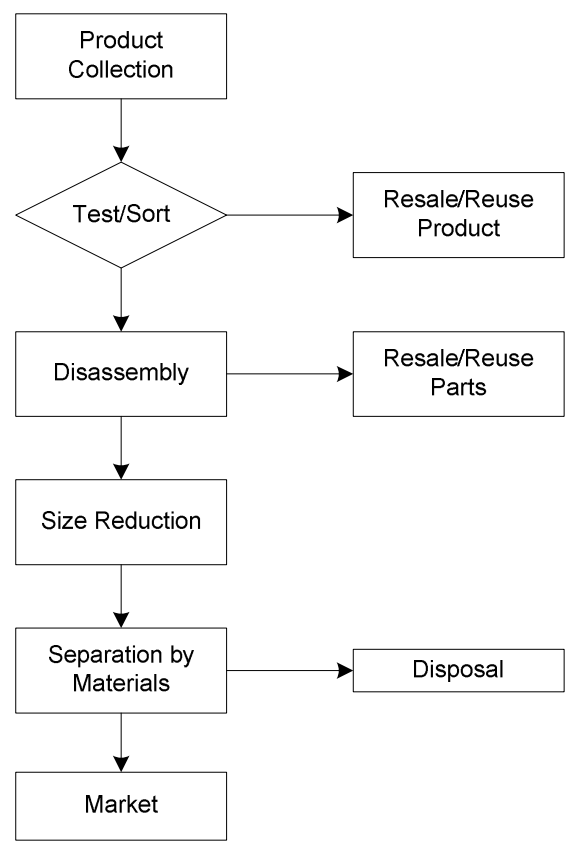

Figure 1. Simplified flow diagram for the recycling of an electronic product

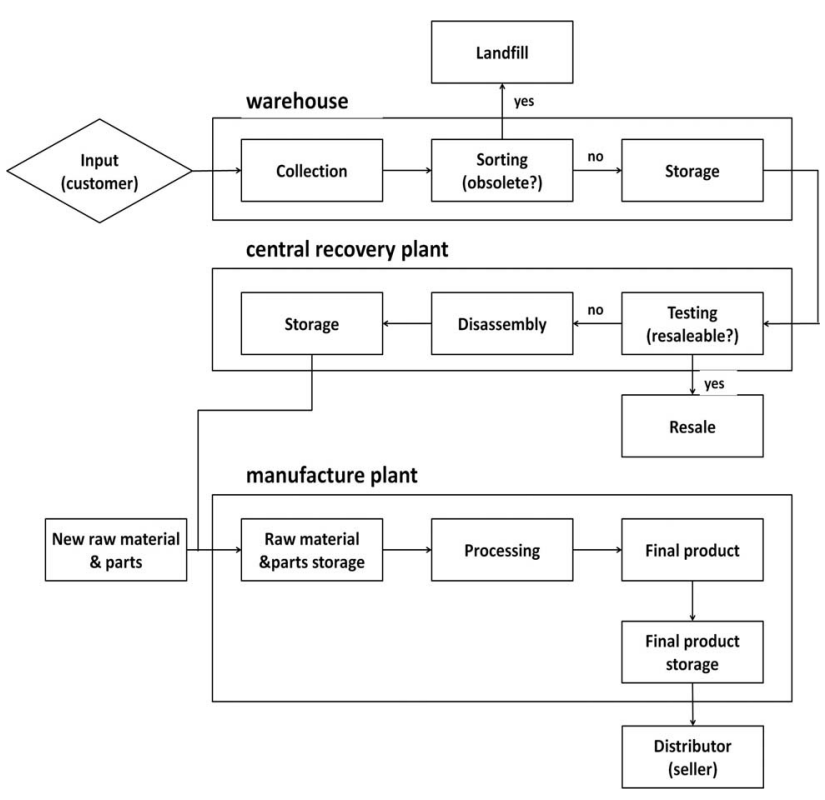

Figure 2. First prototype reverse supply chain network

In this paper, remanufacturing of a product is used as a way to reduce production cost compared to producing new products (in terms of less new material and less manufacturing process required) while reducing environmental cost at the same time.

Based on existing literature, a first prototype of a reverse supply chain network for the computer industries 
is presented in Figure 2. Marcotte et al. [3] described several parties that are involved in reverse supply chains such as computer users, re-transformers and brokers. In this paper, a computer user described the input for a returned product, re-transformers were where all recovery activities took place (called a central recovery centre) and brokers were a second market.

\section{COMPANY BACKGROUND}

The company considered in this paper is based on case study from 2010 [20]. The company offers consumers a wide range of computing products and services. This paper concentrates on the refurbishment of returned laptops as one of the company activities.

The life-cycle of a typical laptop is 6 months, making the product range's obsolescence rate high. Returns are received from customers as convenience returns when they change their minds or as defective returns. There are also other returns, usually from overstocks or stock adjustments. The last category is demonstration returns.

Computer hardware reverse supply chains have an obstacle which is challenging. There is uncertainty about both demand and offer. Both the arrival times and the quantities of returned computers are usually unknown ahead of time and generally difficult to predict. Computers are returned from a variety of heterogeneous scattered sources such as individual computer owners as well as small or large businesses and organisations owning significant computer parks. Overall, the disposal and return rates are difficult to predict. The demand rates for computer hardware, from brand new to refurbished and recycled, are also difficult to predict. The quality of a returned product or part is hard to assess and varies significantly, directly impacting on potential market value [3]. These returns are periodically collected by resellers and shipped to a recovery centre. All used products undergo technical testing and repair as necessary.

\section{MATHEMATICAL MODEL}

The products are revised, classified and organized by the corresponding disposal and re-manufacturing strategy. Products of good quality for remanufacturing are disassembled and processed until they become materials and assemblies ready to be shipped to manufacturing plants. This action takes place at the Recovery Centre.

At a store or shop where returned products are collected, sorting is the first stage for returned products. An obsolete product will be sent to landfill, while other products will go to the central recovery plant for the next process.

Returned products from shop or store arrive at the recovery plant. Here once again returned product are sorted between re-sale-able products and other products. Re-sale-able products will be refurbished before entering the second market. While, others undergo a disassembly process. In that process, few stages are needed. Figure 3 shows the disassembly processes in a recovery centre. Useful parts are separated from other parts during the disassembly process. Useful parts are refurbished and tested for re-use at a manufacturing plant. Other parts will be scrapped to extract useful raw material from the parts. All parts and material from the recovery centre are sent to a manufacturing plant to be used as raw material and parts.

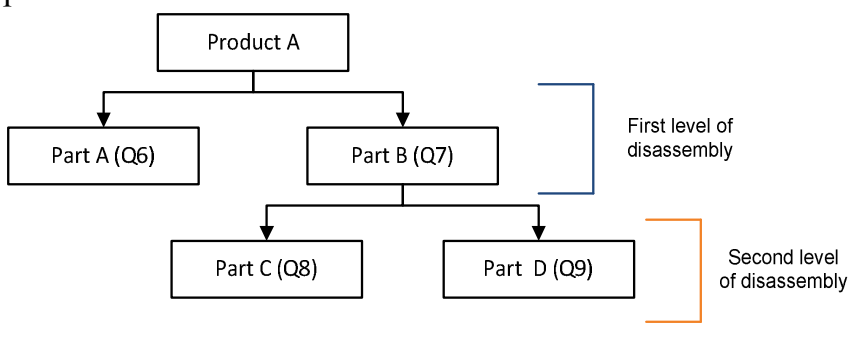

Figure 3. Level of disassembly process

At the manufacturing plant, the additional material from returned products is used together with new materials to make new products that are stored and then shipped to distributors for sale. Figure 4 shows a general model of product flow.

Company performance is considered with respect to cost optimisation. The objective of the company is to minimise cost. The following mathematical model was created based on the case study. The model can be used to consider minimising cost.

The mathematical model is the sum of all the costs associated with the process.

$$
\begin{aligned}
& \text { Cost }= \\
& \sum_{z=1}^{Z} \sum_{i=1}^{I} \sum_{t=1}^{T} Q_{1 z i t} A_{\text {rit }}+ \\
& \sum_{z=1}^{Z} \sum_{r=1}^{R} \sum_{i=1}^{I} \sum_{t=1}^{T} Q_{2 z r i t} B_{\text {zrit }}+ \\
& \sum_{z=1}^{Z} \sum_{l=1}^{L} \sum_{i=1}^{I} \sum_{t=1}^{T} Q_{3 z l i t} C_{z l i t}+ \\
& \sum_{r=1}^{R} \sum_{i=1}^{I} \sum_{t=1}^{T} Q_{4 r i t} D_{r i t}+\sum_{r=1}^{R} \sum_{i=1}^{I} \sum_{t=1}^{T} Q_{4 r i t} E_{r i t}+ \\
& \sum_{r=1}^{R} \sum_{i=1}^{I} \sum_{t=1}^{T} Q_{5} \text { rit } F_{\text {rit }}+\sum_{r=1}^{R} \sum_{i=1}^{I} \sum_{t=1}^{T} Q_{5 r i t} G_{\text {rit }}+ \\
& \sum_{r=1}^{R} \sum_{i=1}^{I} \sum_{t=1}^{T} Q_{5 r i t} H_{r i t}+\sum_{r=1}^{R} \sum_{i=1}^{I} \sum_{t=1}^{T} Q_{6 r i t} J_{r i t}+ \\
& \sum_{r=1}^{R} \sum_{i=1}^{l} \sum_{t=1}^{T} Q_{7 r i t} K_{r i t}+\sum_{r=1}^{R} \sum_{i=1}^{l} \sum_{t=1}^{T} Q_{8 r i t} N_{\text {rit }}+ \\
& \sum_{r=1}^{R} \sum_{l=1}^{L} \sum_{i=1}^{I} \sum_{t=1}^{T} Q_{\text {grlit }} A A_{\text {rlit }}+ \\
& \sum_{r=1}^{R} \sum_{o=1}^{O} \sum_{i=1}^{I} \sum_{t=1}^{T} Q_{5 \text { roit }} A B_{\text {roit }}+ \\
& \sum_{r=1}^{R} \sum_{i=1}^{I} \sum_{t=1}^{T} Q_{10 r i t} A C_{\text {rit }}+ \\
& \sum_{r=1}^{R} \sum_{m=1}^{M} \sum_{i=1}^{I} \sum_{t=1}^{T} Q_{10 r m i t} A D_{r m i t}+ \\
& \sum_{r=1}^{R} \sum_{o=1}^{O} \sum_{i=1}^{I} \sum_{t=1}^{T} Q_{11 \text { roit }} A E_{\text {roit }}+ \\
& \sum_{r=1}^{R} \sum_{m=1}^{M} \sum_{i=1}^{I} \sum_{t=1}^{T} Q_{12 r m i t} A F_{r m i t}+ \\
& \sum_{s=1}^{S} \sum_{i=1}^{I} \sum_{t=1}^{T} Q_{13 s i t} A G_{s i t}+ \\
& \sum_{s=1}^{S} \sum_{i=1}^{I} \sum_{t=1}^{T} Q_{14 s i t} A H_{s i t}+ \\
& \sum_{m=1}^{M} \sum_{i=1}^{I} \sum_{t=1}^{T} Q_{15 m i t} A I_{m i t}+ \\
& \sum_{m=1}^{M} \sum_{i=1}^{l} \sum_{t=1}^{T} Q_{16 m i t} A J_{m i t}+ \\
& \sum_{m=1}^{M} \sum_{i=1}^{I} \sum_{t=1}^{T} Q_{17 m i t} A K_{\text {rit }}+ \\
& \sum_{m=1}^{M} \sum_{i=1}^{I} \sum_{t=1}^{T} Q_{18 m i t} A L_{m i t}+ \\
& \sum_{m=1}^{M} \sum_{x=1}^{X} \sum_{i=1}^{I} \sum_{t=1}^{T} Q_{19 m x i t} A M_{m x i t}
\end{aligned}
$$




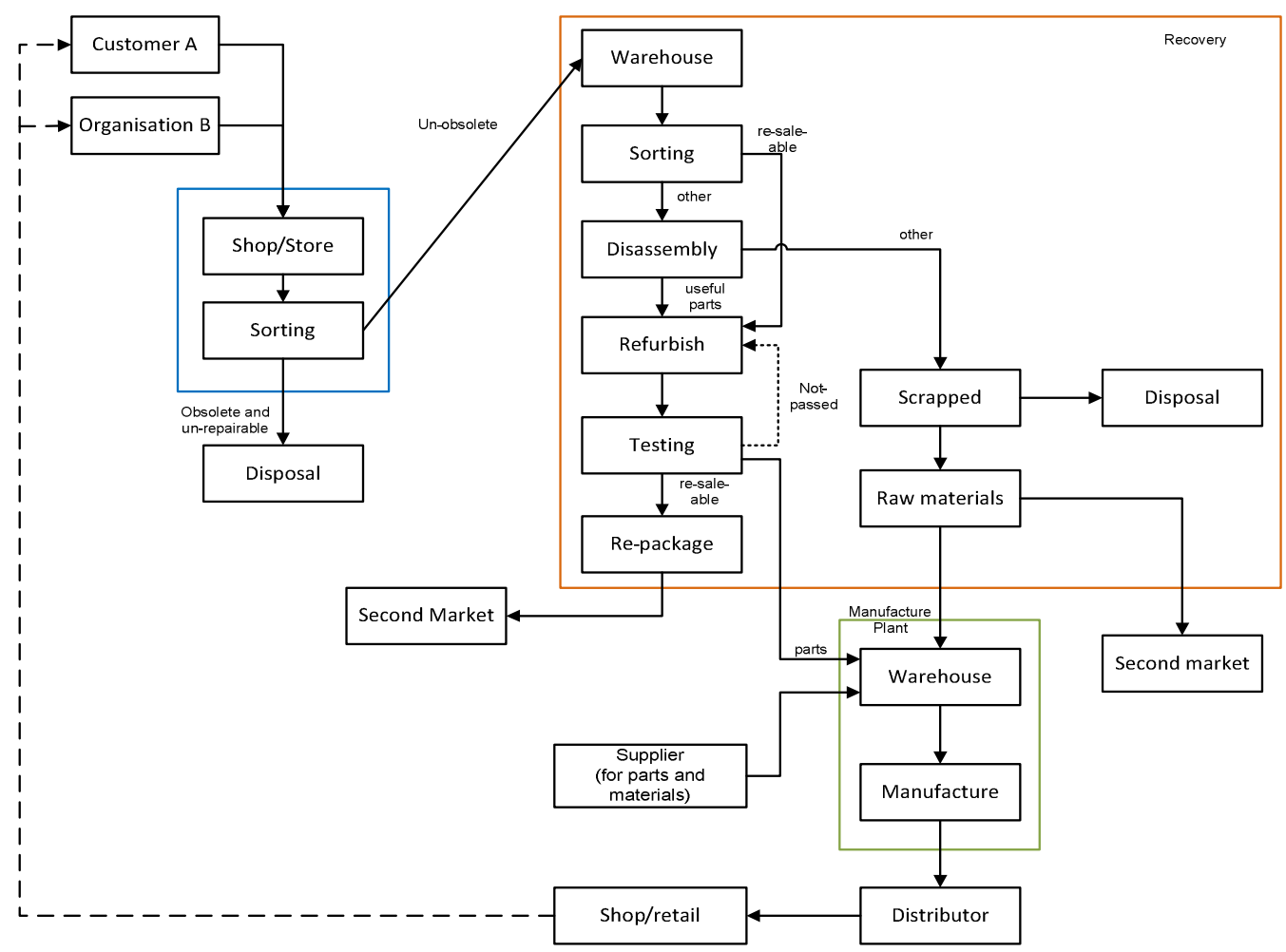

Figure 4. General Model of Product Flows

$\mathrm{Z}$ is the number of stores or shops as collecting points. $\mathrm{R}$ is the number of Recovery Centres and $\mathrm{M}$ is the number of manufacturing plants. $\mathrm{O}$ is the number of routes to second markets and $\mathrm{L}$ is the number of landfill sites. $\mathrm{S}$ is the number of suppliers and $\mathrm{X}$ is the number of distributors. $I$ is the number of types of products. $T$ is the number of periods of time.

A is the sorting cost for returned products at the collecting point. $\mathrm{D}$ is the holding cost at a recovery centre warehouse and $\mathrm{E}$ is sorting cost at recovery centres. F, G and $\mathrm{H}$ are repairing, testing and re-packaging costs for resale-able units at a recovery centre. $J$ is disassembly process cost at a recovery centre and $\mathrm{K}$ is refurbishing cost at a recovery centre. $\mathrm{N}$ is the cost of the scrapping process at a recovery centre. AC is the holding cost for reuse-able parts at a recovery centre.

The transportation costs are: $\mathrm{B}=$ transportation cost from collecting point to recovery centre; $\mathrm{C}=$ transportation cost from collecting point to landfill; $\mathrm{H}=$ transportation cost to landfill; $\mathrm{V}=$ transportation cost from manufacture plant to distributor; $\mathrm{AA}=$ transportation cost from recovery centre to landfill; $\mathrm{AB}=$ transportation cost for re-sale-able units from recovery centre to second market; $\mathrm{AD}=$ transportation cost from recovery centre to manufacturing plant; $\mathrm{AE}=$ transportation cost for raw material from recovery centre to second market ; $\mathrm{AF}=$ transportation cost for raw material from recovery centre to manufacture plant; $\mathrm{AM}=$ transportation cost for final products from manufacture plant to distributors.
AG is the purchasing cost of parts from a supplier and $\mathrm{AH}$ is the purchasing cost of raw materials from a supplier. AI is the holding cost of parts at a manufacture plant and $\mathrm{AJ}$ is the holding cost of raw materials at a manufacture plant. $\mathrm{AK}$ is the production cost at a manufacture plant and AL is the holding cost for final products at a manufacture plant warehouse.

Q1 is the number of units of returned products and Q2 is the number of units being refurbished. Q3 is the number of obsolete units. Q4 is the number of units arriving at a recovery centre and Q5 is the number of re-sale-able units. Q6 is the number of units being disassembled and Q7 is the number of parts at the recovery centres are being refurbished. Q8 is number of units being scrapped and Q9 is the number transported to landfill. Q10 is the number of reuse-able parts. Q11 is raw material that transported to second market and Q12 is raw material sent to a manufacturing plant. Q13 is the number of parts purchased from suppliers and Q14 is the raw materials purchased from suppliers. Q15 is the number of parts at a manufacturing plant warehouse and Q16 is the raw material at a manufacturing plant warehouse. Q17 is the number of units produced and Q18 is the number of final product at manufacturing plant warehouse. Q18 is the number of units being transported to distributors from a manufacture plant.

The objective of this model was to minimise the cost subject to the capacity of the recovery centre warehouse; manufacture plant warehouse; recovery centre labour available; manufacture production capacity; and demand for new products. 


\section{TESTING}

Secondary data was used for testing due to a lack of primary data. An excel program was produced to represent the models. A screenshot of a worksheet is shown in figure 5. Demand for the product was calculated and from this demand, the forecast for demand was counted and shown in Figure 6.

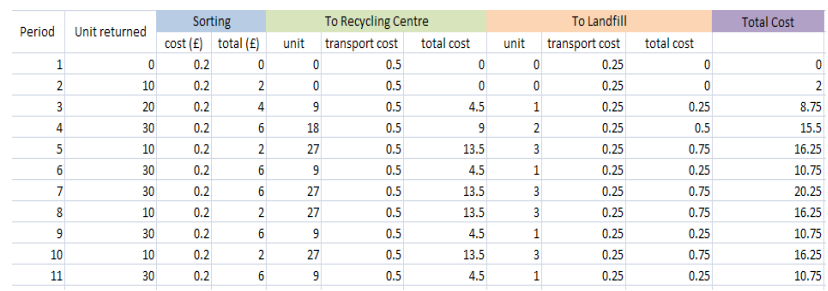

Figure 5. Worksheet screenshot

Demand Forecast

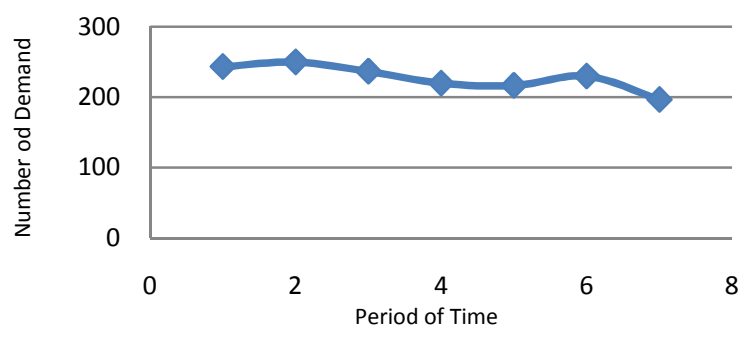

Figure 6. Demand Forecast

The forecast demand was applied to the model as the demand.

\section{RESULT}

The demand was applied to the mathematical model to see how the cost was affected by returned products. The model was tested with a low number of return products and a high number of returned products. Total cost per period of time can be seen in Figure 7 for the high number of returned products and Figure 8 for the low number of returned products.

Total Cost

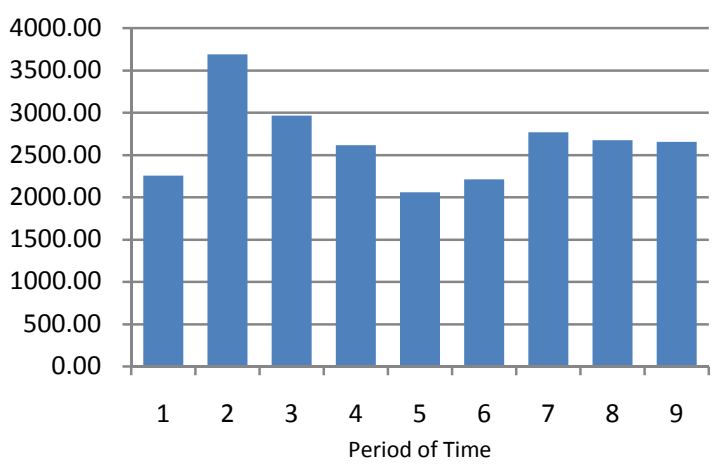

Figure 7. Total Cost for High Number of Return Products

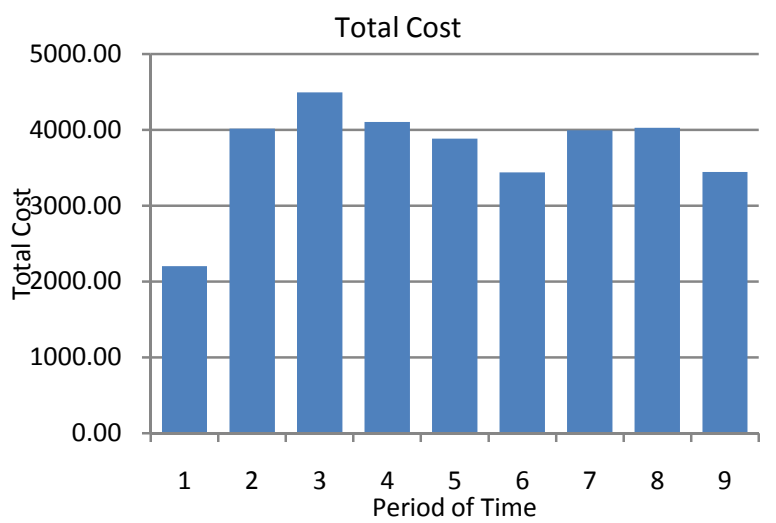

Figure 8. Total Cost for Low Number of Return Products

These graphs, are discussed in the next sections.

\section{CONCLUSION}

With the same demand, total cost will be different for each product. Returned products significantly affect total cost. The difference between a high number of returned compared with a low number of returned products affected the total cost as shown in Figure 9.

At the beginning of a period of time, it could be seen that cost for a low return product flow is lower than the cost for a high return product flow. That is because there is no cost in the Recovery Centre for a low return product flow. In the Recovery Centre, total cost for a low returned product flow is lower than for a high returned product flow. Therefore, in future work an actual profit from selling the raw material from the scrapping process needs to be added to see how it affects Recovery Centre costs. As well as how re-sale-able products affect total cost.

In the next period of time, Figure 8 shows that a high returned product flow lowers the total cost compare to a low returned product flow. With re-usable parts from the Recovery Centre, new parts procurement will be reduced. That leads to cost minimisation and more effective supply chain performance.

The model needs some improvement, for example:

- Primary data could be improved.

- It would be better if sale price to second market and distributor is known to see how it affects profit.

- More specific investigation of how parts of the process affect the most total cost could be considered.

This is the first time that an attempt to measure performance in reverse supply chains in the computer hardware industry has been published. The simple mathematical model was created due to lack of references about reverse supply chains in the computer industry as well as in performance measurement in reverse supply chains. 


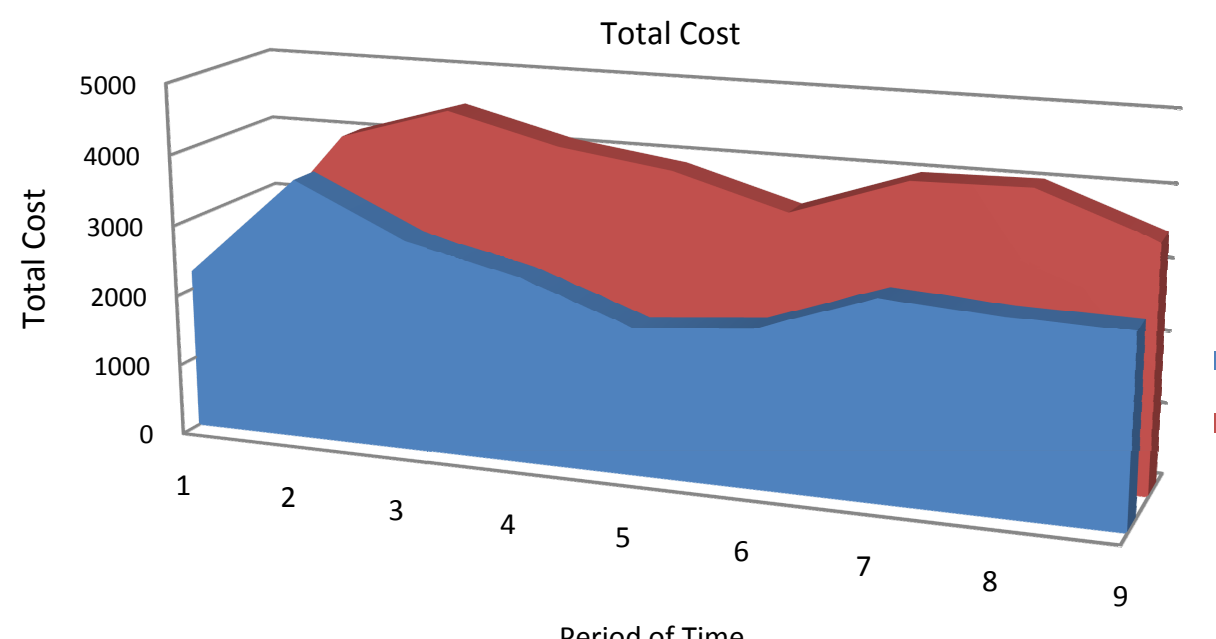

- High return prodet

- Low return product

Figure 9. Total Cost for High Return Product Vs Low Return

Most literature in the computer industry that focused on reverse supply chains only mentioned metrics and none of the references described how to measure performance. Most references only focused on a recovery centre without considering the re-manufacturing process. In this paper, simple mathematic models are presented for remanufacturing processes in general.

In the future, more could be explored, such as: which process in the reverse supply chain affect the systems performance the most and how to measure the performance of reverse supply chain with environmental regulation as the objective.

\section{ACKNOWLEDGMENT}

Butar Butar thanks the Directorate General of Higher Education Indonesia for facilitating and supporting the study.

\section{REFERENCES}

[1] Shear, H., T. Speh, and J. Stock, Many happy (product) returns. Harvard business review, 2002. 80(7): p. 16-17.

[2] Lee, C.-H., et al., An overview of recycling and treatment of scrap computers. Journal of hazardous materials, 2004. 114(1): p. 93-100.

[3] Marcotte, S., M.-E. Hallé, and B. Montreuil, Computer Hardware Reverse Logistics: A Field Study of Canadian Facilities. Proceedings of the Progress in Material Handling Research, 2008: p. 370-389.

[4] Kang, H.-Y. and J.M. Schoenung, Electronic waste recycling: A review of US infrastructure and technology options. Resources, Conservation and Recycling, 2005. 45(4): p. 368-400.

[5] Butar, M.B. and D. Sanders, Improving Green Computing in Business Intelligence by Measuring Performance of Reverse Supply Chains. GSTF Journal on Computing, 2013. 3(1).

[6] Guide, V.D.R., T.P. Harrison, and L.N. Van Wassenhove, The challenge of closed-loop supply chains. Interfaces, 2003. 33(6): p. 3-6.
[7] Blumberg, D.F., Introduction to management of reverse logistics and closed loop supply chain processes. 2004: CRC Press.

[8] Van Wassenhove, L.N. and V. Guide, Closed-loop supply chains. 2003: Pittsburgh.

[9] Guide Jr, V.D.R.a.L.N.v.W., The reverse supply chain. Harvard Business Review, 2002: p. 25-26.

[10] Guide, V.D.R. and L.N. Van Wassenhove, Closed-loop supply chains: practice and potential. Interfaces, 2003. 33(6): p. 1-2.

[11] Rogers, D.S. and R. Tibben-Lembke, An examination of reverse logistics practices. Journal of business Logistics, 2001. 22(2): p. 129-148.

[12] 12. De Brito, M.P. and R. Dekker, A framework for reverse logistics. 2004: Springer.

[13] Moore, R., Reverse Logistics-the least used differentiator. A UPS Supply Chain Solutions White Paper, Alpharetta, 2005.

[14] Fleischmann, M., et al., Quantitative models for reverse logistics: a review. European journal of operational research, 1997. 103(1): p. 1-17.

[15] Rahimifard, A., S. Newman, and S. Rahimifard, $A$ webbased information system to support end-of-life product recovery. Proceedings of the Institution of Mechanical Engineers, Part B: Journal of Engineering Manufacture, 2004. 218(9): p. 1047-1057.

[16] Thierry, M., et al., Strategic issues in product recovery management. California management review, 1995. 37(2).

[17] Cuthberston, R. and W. Piotrowicz, Supply chain best practices - identification and categorisation of measures and benefits. International Journal of Productivity and Performance Measurement, 2008: p. 389-404.

[18] Stock, J.R., The 7 deadly sins of reverse logistics. Material handling management, 2001: p. 55.

[19] Stock, J.R. and J.P. Mulki, Product returns processing: an examination of practices of manufacturers, wholesalers/distributors, and retailers. Journal of business Logistics, 2009. 30(1): p. 33-62.

[20] Saibani, N., Performance Measurement for Reverse and Closed -loop Supply Chains. 2010, University of Nottingham. 